\title{
Rating systems, procyclicality and Basel II: an evaluation in a general equilibrium framework*
}

Chiara Pederzoli

University of Milano-Bicocca and CEFIN, Piazza

dell'Ateneo Nuovo 1, 20126 Milano, tel. +39026448 3184, fax +390264483105, chiara.pederzoli@unimib.it

Costanza Torricelli

University of Modena and Reggio Emilia and CEFIN, Via

Berengario 51, 41100 Modena, tel. +39059 2056r33, fax

+39059 2056937, torricelli.costanza@unimore.it

Dimitrios P. Tsomocos

University of Oxford, Saïd Business School and St.

Edmund Hall, tel. +44 (0) 1865288 932, fax +44 (0) 1865

288 805, dimitrios.tsomocos@sbs.ox.ac.uk

June 2008

\footnotetext{
*The authors are grateful to Charles Goodhart and to seminar participants at the VIII SAET Conference, the XXII EURO Conference, the Workshop on Credit risk models (Rimini), the Second Workshop CEFIN, the BOMOPA Workshop, the Finlawmetrics 2008 conference and the XVII European Workshop on General Equilibrium for helpful comments. However, all remaining errors are ours. Chiara Pederzoli and Costanza Torricelli gratefully acknowledge MIUR-PRIN 2005 for financial support.
} 


\begin{abstract}
The introduction of Basel II has raised concerns about the potential impact of risk-sensitive capital requirements on the business cycle. Several approaches have been proposed to assess the procyclicality issue. In this paper, we adopt a general equilibrium model and conduct comprehensive analysis of different proposals. We set out a model that allows to evaluate different rating systems in relation to the procyclicality issue. Our model extends previous models by analysing the effects of different rating systems on banks' portfolios (as in Catarineu-Rabell et al. 2005) and the contagion effects relevant to financial stability (as in Goodhart et al. 2005). The paper presents comparative statics results comparing a cycle-dependent and a neutral rating system from the point of view of banks profit maximization. Our results suggest that banks' preferences about point in time or through the cycle rating systems depend on the banks' characteristics and on the business cycle conditions in terms of expectations and realizations.
\end{abstract}

June 2008 


\section{Introduction}

The introduction of Basel II has raised concerns about the possible impact of risk-sensitive capital requirements on the real economy: since it is widely recognised that credit risk factors are affected by economic conditions (see e.g. Bangia et al. 2002, and Nickell et al. 2000), risk sensitive capital requirements fluctuate over the business cycle, potentially causing an amplification of the cycle through the lending channel. Concerns about procyclicality have been expressed by several authors (e.g. Danielsson et al. 2001, Borio et al. 2001, Repullo and Suarez 2007). In particular, the concerns focus on the possible exacerbation of recessions due to credit shortage ${ }^{1}$.

Most studies on financial stability and procyclicality in connection with Basel II have focused on the role of the rating system: the debate has basically developed around the comparison between through the cycle (ttc) versus point in time (pit) rating systems and several proposals have been made to deal with the procyclicality of the capital requirements (e.g. Kashyap and Stein (2004), Pederzoli and Torricelli (2005), Gordy and Howells (2006)). Gordy and Howells (2006) highlight three possible ways to deal with procyclicality under the Internal Rating Based (IRB) Basel framework. They mention either smoothing the input to the capital function (mainly adopting a ttc rating philosophy) or flattening the capital function itself (by reducing the sensitivity to the default probability). These two approaches have partly been followed in moving from the first to the last version of the document by the Basel Committee on Banking Supervision (see BCBS 2006). However they both lead to a loss in risk sensitivity, since they rely on the trade-off between risk-sensitivity and procyclicality. Gordy and Howells (2006) suggest smoothing the output of the capital function for regulatory purpose and allows to avoid losses in terms of transparency. Pederzoli and Torricelli (2005) propose an alternative approach where a business cycle forecast is included into the estimation of default probabilities: this is consistent with the views expressed by Borio et al.(2001) that risk is built up during expansions and the high default rates observed during recessions are just a manifestation of that risk. According to this view, a risk measure should be high in expansion before a recession and low at the bottom of the cycle in anticipation of an expansion. Hence a capital requirement based on such a risk measure would decline at the bottom of the cycle helping the economy out of the recession and act as a build-in-stabilizer in the banking sector.

\footnotetext{
${ }^{1}$ Recent papers stress the importance of setting up an appropriate framework for monitoring procyclicality, e.g. Masschelein (2007).
} 
However, the trade-off between procyclicality and risk-sensitivity of capital requirements, emerging from the dependence of credit risk factors on the business cycle, needs to be analysed further. A few papers have provided an evaluation of the different rating proposals in terms of procyclicality. Gordy and Howells (2006) compare different rating philosophies by considering banks with different exogenous investment strategies and thus disregard the feedback mechanism of capital requirements on banks lending behaviour and, hence, on the economy. In order to overcome this limitation, a general equilibrium model is the appropriate framework for a comprehensive analysis of the procyclicality issue. Catarineu-Rabell et al. (2005) analyse the procyclicality issue by comparing different rating systems from the banks' profitability point of view: within a 2-periods, 2-states GE model with one bank, one corporate and one household, they find that banks would prefer pit rather than ttc rating system, with dangerous consequences in terms of procyclicality. However they do not account for the heterogeneity of agents, while we think this is an important feature in this context. The model used in Catarineu-Rabell et al. (2005) stems from the general theoretical model presented in Tsomocos (2003). Goodhart et al.(2004) present a smaller version of the original model (Goodhart et al. 2006), which allows to obtain numerical solution while Goodhart et al. (2005) simplify the non-banking agents problems to reduced-form equations in order to perform a calibration against real UK banking data. In sum, models proposed so far in the literature do not allow consideration of both the effects of different rating systems on banks'portfolios (as e.g. CatarineuRabell et al. 2005) and contagion effects relevant to financial stability (as e.g. Goodhart et al. 2005).

The purpose of this paper is to build on these models in order to develop a framework to evaluate different rating proposals in conjunction with the procyclicality issue.

The structure of the paper is as follows. In the following Section we present the model and the agents' optimization problems. Section 3 presents the model solution (i.e. the initial equilibrium) and Section 4 is devoted to the evaluation of different rating systems by means of comparative statics analysis. The last Section concludes.

\section{The model}

The model we propose is a general equilibrium model of an exchange economy with money and banks. Following the structure of the general model in Goodhart et. al (2006) and adopting some simplifications along the lines of Catarineu-Rabell et. al. (2005), three sectors are considered: the banking sector, the corporate sector and the household. The model 
includes corporate loans, interbank, and deposit markets; moreover, corporates and household trade perishable goods on the commodity market. While banks maximize a function of their profit, corporate and households aim at maximizing their intertemporal consumption. The model is characterized by heterogeneity of the agents, limited participation, and endogenous default. The structure of the model is as follows:

1) Two periods $t=0,1$

2) Two states of the world in $\mathrm{t}=1 \mathrm{~s}=1$ (expansion) or 2 (recession)

3) Two banks: bank $\gamma$ is a net borrower in the interbank market; bank $\delta$ is a net lender in the interbank market; both banks maximize expected profits in $\mathrm{t}=1$ subject to penalties on default;

4) Two corporates $\alpha, \beta$ : each corporate borrows from a single prespecified bank (limited participation hypothesis) and its payoff is the expected utility of consumption minus a default penalty;

5) One household $\phi$ : the household deposits in a single bank and its payoff is the expected utility of consumption;

6) Central bank/regulator exogenously determines money supply ${ }^{2}$ $M$, minimum capital requirements in terms of capital adequacy ratio $K$ (such as the $8 \%$ imposed by Basel II), default penalties $\lambda$.

The optimization problems of the agents are presented in the following subsections.

\subsection{Banks' optimization problem}

Both banks maximize the expected profits and are subject to a capital requirements constraint in the Basel II style. The banks differ with respect to their clients. Bank $\gamma$ lends to corporate $\alpha$ whereas bank $\delta$ to corporate $\beta$. Moreover, they play different roles in the deposit and interbank markets.

In order to formalize the problem for bank $\gamma$, let the relevant variables be defined as follows.

$p_{s}=$ probability of state $\mathrm{s} ;$

$m_{\alpha}^{\gamma}=$ loan extension to corporate $\alpha$;

$\mu^{\gamma}=$ money borrowed on the interbank market;

$v_{s}^{\gamma}=$ repayment rate of bank $\gamma$ in state $\mathrm{s}$;

$v_{s}^{\alpha}=$ repayment rate of corporate $\alpha$ in state s;

$c_{0}^{\gamma}=$ capital of bank $\gamma$ in $\mathrm{t}=0$;

$\lambda^{\gamma}=$ default penalty for bank $\gamma$;

$\rho=$ interbank interest rate;

\footnotetext{
${ }^{2}$ We could have used the reverse policy, i.e., setting the interbank interest rate and letting the money supply to vary. However, the results would be qualitatively the same but the absolute levels would be bigger since the price effect of the interbank market would be more pronounced.
} 
$r_{m}^{\gamma}=$ interest rate on corporate laons;

$k^{\gamma}=$ bank $\gamma^{\prime}$ capital ratio;

$w=$ Basel II credit risk weight;

$\pi_{s}^{\gamma}=$ profit of bank $\gamma$ in state s;

$a^{\gamma}=$ bank $\gamma$ coefficient of risk aversion;

$\Delta(x)=$ difference between right hand side and left hand side of inequality $x$.

The profit of bank $\gamma$ in the generic state $\mathrm{s}$ is defined in equation 1 : it results as the difference between the amounts of money received and paid by bank $\gamma$ in $t=1$ plus the money at hand from the first period.

$$
\pi_{s}^{\gamma}=v_{s}^{\alpha}\left(1+r_{m}^{\gamma}\right) m_{\alpha}^{\gamma}-v_{s}^{\gamma} \mu^{\gamma}+\left(\frac{\mu^{\gamma}}{1+\rho}+c_{0}^{\gamma}-m_{\alpha}^{\gamma}\right)
$$

The bank $\gamma$ optimization problem is defined as follows:

$$
\max _{m_{\alpha}^{\gamma}, \mu^{\gamma}, v_{1}^{\gamma}, v_{2}^{\gamma}} \Pi^{\gamma}=\sum_{s} p_{s}\left\{\pi_{s}^{\gamma}-a^{\gamma}\left(\pi_{s}^{\gamma}\right)^{2}-\lambda^{\gamma} \max \left[\mu^{\gamma}\left(1-v_{s}^{\gamma}\right), 0\right]\right\}
$$

s. $t$.

$$
\begin{gathered}
m_{\alpha}^{\gamma} \leq \frac{\mu^{\gamma}}{1+\rho}+c_{0}^{\gamma} \\
v_{s}^{\gamma} \mu^{\gamma} \leq v_{s}^{\alpha}\left(1+r_{m}^{\gamma}\right) m_{\alpha}^{\gamma}+\Delta(3) \quad s=1,2 \\
k^{\gamma} \geq K
\end{gathered}
$$

The bank maximizes its expected payoff, as defined in equation 2 . In particular, the payoff in state $s$ is defined by a quadratic function of state $s$ profit less a penalty in case of default on the interbank debts. The bank chooses the amount of money to borrow from the interbank market $\left(\mu^{\gamma}\right)$, the amount of money to invest in loans to corporate $\left(m_{\alpha}^{\gamma}\right)$ and the its repayment rates $\left(v_{1}^{\gamma}, v_{2}^{\gamma}\right)$ subject to budget and capital requirements constraints. We also set $p_{s}=0.5$ for $s=1,2$ in order to find the initial equilibrium. Had we used different state probabilities, e.g., $p_{1}=0.9$ and $p_{2}=0.1$, we would have only exacerbated the results presented in Section 4 . In $\mathrm{t}=0$ investments are limited by money availability, as from the budget constraint in equation 3. Equation 4 states that revenues from investments in $t=1$ must cover the repayments to creditors. The capital requirements constraint, defined in equation 5, mimics the Basel 
II requirement and applies in $\mathrm{t}=0$. Since credit risk for banks arises from corporates defaultability, the capital ratio, defined in equation 6 , accounts for investments in corporate loans.

$$
k^{\gamma}=\frac{c_{0}^{\gamma}}{w\left(1+r_{m}^{\gamma}\right) m_{\alpha}^{\gamma}}
$$

The term $w$ represents a credit risk measure for corporate loans and is modelled as an increasing function of the corporate $\alpha$ ' probability of default. Specifically, equation 7 defines the risk weight $w$ for exposure towards corporates as a function the corporate's probability of default $(P D)$ which mimics the Basel II formula ${ }^{3}$.

$$
w=1.2 P D-1.9 P D^{2}
$$

In equation $7, P D$, which is the input to the Basel capital function, represents the expected default rate over the second period horizon. In order to model a forward-looking ${ }^{4}$ pit rating system, the corporate $\alpha$ 's $P D$ is defined in equation 8 , where $p_{2}$ is the recession probability (and the expansion probability is $p_{1}=1-p_{2}$ )

$$
P D=E\left(1-v_{s}^{\alpha}\right)=p_{1}\left(1-v_{1}^{\alpha}\right)+p_{2}\left(1-v_{2}^{\alpha}\right)
$$

Therefore, the $P D$ depends on the business cycle forecast over the horizon considered through the recession probability and on the corporate's endogenous default in the two states.

On the contrary a ttc rating system does not consider any dependence either on forecast or on current economic conditions. The risk weight is again defined as in (7), but the $P D$ in (8) is defined by fixing the state probabilities to 0.5 (i.e. no biased forecasts are considered) and the endogenous repayment rates to the equilibrium values. Therefore in the comparative statics analysis changes in the recession probability do not affect risk weights undet the ttc rating system.

We now turn to the second bank's optimization problem. Bank $\delta$ is a net lender on the interbank market and it also collects deposits

\footnotetext{
${ }^{3}$ The formula used for the risk weight is a proxy for the Basel II formula ( $M=1$, $\mathrm{LGD}=45 \%$ ): the introduction of the actual Basel formula would be intractable from a computational point of view when solving the optimization problem. However, we believe the distorsion is not relevant as the main features of the Basel function are preserved, i.e., the function we use is in fact concave and it reaches the maximum at the same point. The function is decreasing in the default probability from a certain level onward, as the unexpected loss in Basel II. However, the function is increasing for realistic values of the PD.

${ }^{4}$ Forward looking in that it accounts for a forecast of the business cycle rather than for current economic conditions.
} 
from household. We assume that the bank cannot default on deposits ${ }^{5}$. Moreover, while corporate $\alpha$ is the counterpart of bank $\gamma$, corporate $\beta$ is the counterpart of bank $\delta$ (limited participation hypothesis).

In order to formalize the bank $\delta$ optimization problem, let the relevant variables of bank $\delta$ be:

$m_{\beta}^{\delta}=$ credit extension to corporate $\beta$;

$d^{\delta}=$ credit extension to bank $\gamma$;

$\mu_{d}^{\delta}=$ money from deposits;

$r_{m}^{\delta}=$ interest rate on laons to corporate;

$r_{d}^{\delta}=$ deposit interest rate;

$v_{s}^{\beta}=$ repayment rate of corporate $\beta$ to its creditor in state s;

$c_{0}^{\delta}=$ capital of bank $\delta$ in $\mathrm{t}=0$;

$k^{\delta}=$ bank $\delta$ ' capital ratio;

$\pi_{s}^{\delta}=$ profit of bank $\delta$ in state s;

$a^{\delta}=$ bank $\delta$ coefficient of risk aversion.

As for bank $\gamma$, the profit of bank $\delta$ in state $\mathrm{s}(\mathrm{t}=1)$ is defined by the net revenues in equation 9 .

$$
\pi_{s}^{\delta}=v_{s}^{\beta}\left(1+r_{m}^{\delta}\right) m_{\beta}^{\delta}+v_{s}^{\gamma} d^{\delta}(1+\rho)-\mu_{d}^{\delta}+\left(\frac{\mu_{d}^{\delta}}{1+r_{d}^{\delta}}+c_{0}^{\delta}-m_{\beta}^{\delta}-d^{\delta}\right)
$$

The bank $\delta$ optimization problem is defined as follows:

$$
\max _{m_{\beta}^{\delta}, \mu_{d}^{\delta}, d^{\delta}} \Pi^{\delta}=\sum_{s} p_{s}\left[\pi_{s}^{\delta}-a^{\delta}\left(\pi_{s}^{\delta}\right)^{2}\right]
$$

s. $t$.

$$
\begin{gathered}
m_{\beta}^{\delta}+d^{\delta} \leq \frac{\mu_{d}^{\delta}}{1+r_{d}^{\delta}}+c_{0}^{\delta} \\
\mu_{d}^{\delta} \leq v_{s}^{\beta}\left(1+r_{m}^{\delta}\right) m_{\beta}^{\delta}+v_{s}^{\gamma} d^{\delta}(1+\rho)+\Delta(11) \quad s=1,2 \\
k^{\delta} \geq K
\end{gathered}
$$

Bank $\delta$ maximizes its expected payoff, which is a quadratic function of profits as it is shown in equation 10. Equation 11 represents the

\footnotetext{
${ }^{5}$ This hypothesis is equivalent to having a very high default penalty on deposits. Put differently, even minimal default on deposits is commensurate to bankruptcy and closure of the bank.
} 
budget constraint in $\mathrm{t}=0$ and equation 12 states that revenues in $\mathrm{t}=1$ plus money at hand from $t=0$ must cover debts. The capital requirements constraint in equation 13 applies in $t=0$. The risk weighted assets for bank $\delta$ (equation 14) include both exposures towards corporate $\beta$ and bank $\gamma$.

$$
k^{\delta}=\frac{c_{0}^{\delta}}{w\left(1+r_{m}^{\delta}\right) m_{\alpha}^{\delta}+\widetilde{w}(1+\rho) d^{\delta}}
$$

The risk weights $w$ and $\widetilde{w}$ are increasing functions of the default probability of corporate $\beta$ and bank $\gamma$ respectively. The same considerations as in equations 7 and 8 hold.

\subsection{Corporates' optimization problem}

The economy is one without production and stochastic endowments play the role of production output. In order to motivate trade, we will consider the case in our simulations that the corporates are poor in $t=0$ and they receive stochastic commodity and money endowments in $t=1$. Therefore they borrow in $\mathrm{t}=0$ in order to smooth intertemporal consumption. The additional relevant variables for both corporates, indicating with $h$ either corporate $\alpha$ or $\beta$ and with $b$ either bank $\gamma$ or $\delta$ respectively are as follows:

$e_{s}^{h}=$ commodity endowment in $\mathrm{t}=1$;

$m_{s}^{h}=$ monetary endowment in $\mathrm{t}=1$;

$b_{0}^{h}=$ expenditures for commodities in $\mathrm{t}=0$;

$q_{s}^{h}=$ quantity of commodity to sell in $\mathrm{t}=1$;

$\mu^{h}=$ borrowings from the assigned bank;

$v_{s}^{h}=$ repayment rate in $\mathrm{t}=1$;

$a_{l}^{h}(l=0,1,2)=$ corporate $h$ coefficient of risk aversion (in $\mathrm{t}=0$ and in the two states in $\mathrm{t}=1$ );

$g_{0}, g_{1}, g_{2}=$ commodity prices in period $\mathrm{t}=0$ and in the two states of period $\mathrm{t}=1$ respectively.

$x_{0}^{h}=$ corporate $h$ commodity consumption in $\mathrm{t}=0$;

$x_{s}^{h}=$ corporate $h$ commodity consumption in $\mathrm{t}=1$.

The last two variables, representing consumption in the two periods, are defined respectively as $x_{0}^{h}=b_{0}^{h} / g_{0}$ (commodity expenditures over commodity price) and $x_{s}^{h}=e_{s}^{h}-q_{s}^{h}$ (commodity endowment minus commodity sale). The two corporates differ in endowments and risk aversion and they solve the following optimization problem: 
$\max _{b_{0}^{h}, q_{1}^{h}, q_{2}^{h}, \mu^{h}, v_{1}^{h}, v_{2}^{h}} U^{h}=x_{0}^{h}-a_{0}^{h}\left(x_{0}^{h}\right)^{2}+\sum_{s} p_{s}\left\{x_{s}^{h}-a_{s}^{h}\left(x_{s}^{h}\right)^{2}-\lambda^{h} \max \left[\mu^{h}\left(1-v_{s}^{h}\right), 0\right]\right\}$

s. $t$.

$$
\begin{gathered}
b_{0}^{h} \leq \frac{\mu^{h}}{1+r_{m}^{b}} \\
v_{s}^{h} \mu^{h} \leq \Delta(16)+g_{s} q_{s}^{h}+m_{s}^{h} \quad s=1,2
\end{gathered}
$$

Equation 15 states that the corporate chooses the amount of money borrowing to buy commodity in $t=0$, the commodities to sale in $t=1$ and the repayment rates to the bank in order to maximize its utility from consumption subject to a penalty for defaulted loans. The constraints to the optimization problems state that the amount spent for commodity in $t=0$ is bounded by the amount of money borrowed from the bank (equation 16) and that the repayed amounts in $\mathrm{t}=1$ are bounded by revenues from commodity sales plus monetary endowments (equation 17).

\subsection{Households' optimization problem}

The households (indicated by $\phi$ ) are rich agents in period $t=0$ while they have no endowments in $t=1$ : in the first period they sell part of their commodity and deposit money in order to smooth consumption over the second period. Based on the fact that banks which are net lenders in the interbank market collect most of the deposits, we simplify the model by assuming that the household deposits its whole money endowment in bank $\delta$. In the following the relevant variables and the optimization problem are presented:

$e_{0}^{\phi}=$ commodity endowment in $\mathrm{t}=0$;

$m_{0}^{\phi}=$ monetary endowment in $\mathrm{t}=0$;

$d^{\phi}=$ deposits in bank $\delta$;

$b_{s}^{\phi}=$ expenditures for commodities in $\mathrm{t}=1$;

$q_{0}^{\phi}=$ commodity sales in $\mathrm{t}=0$;

$u=$ fixed money expenditures;

$a_{l}^{\phi}(l=0,1,2)=$ household coefficient of risk aversion (in $\mathrm{t}=0$ and in the two states in $\mathrm{t}=1)$;

$x_{0}^{\phi}=$ household commodity consumption in $\mathrm{t}=0$;

$x_{s}^{\phi}=$ household commodity consumption in $\mathrm{t}=1$. 
The last two variables, representing consumption in the two periods, are defined respectively as $x_{0}^{\phi}=e_{0}^{\phi}-q_{0}^{\phi}$ (commodity endowment minus commodity sale) and $x_{s}^{\phi}=b_{s}^{\phi} / g_{s}$ (commodity expenditures over commodity prices).

$$
\max _{d^{\phi}, b_{1}^{\phi}, b_{2}^{\phi}, q_{0}^{\phi}} U^{\phi}=x_{0}^{\phi}-a_{0}^{\phi}\left(x_{0}^{\phi}\right)^{2}+\sum_{s} p_{s}\left[x_{s}^{\phi}-a_{s}^{\phi}\left(x_{s}^{\phi}\right)^{2}\right]
$$

s. $t$.

$$
\begin{gathered}
(a) d^{\phi} \leq m_{0}^{\phi} \quad(b) q_{0}^{\phi} \leq e_{0}^{\phi} \\
b_{s}^{\phi} \leq \Delta(19-a)+g_{0}^{\phi} q_{0}^{\phi}+d^{\phi}\left(1+r_{d}^{\delta}\right)-u \quad s=1,2
\end{gathered}
$$

Equation 18 states that households choose commodity trades and deposit in order to maximize the utility from consumption in both periods. The constraints in $\mathrm{t}=0$ (equation 19) bound the deposit and the commodity sale to the money and commodity endowments respectively. The constraits in $t=1$ (equation 20) bound the expenditures for commodity to the revenues from sales and interests from deposits in $t=0$.

\section{The initial equilibrium}

The initial equilibrium is obtained by simultaneously solving the optimization problems for all the agents and satisfying the market clearing conditions (21)-(24).

$$
\begin{gathered}
g_{0}=\frac{b_{0}^{\alpha}+b_{0}^{\beta}}{q_{0}^{\phi}} \quad g_{s}=\frac{b_{s}^{\phi}}{q_{s}^{\alpha}+q_{s}^{\beta}} \quad s=1,2 \\
1+r_{m}^{\gamma}=\frac{\mu^{\alpha}}{m^{\gamma}} \quad 1+r_{m}^{\delta}=\frac{\mu^{\beta}}{m^{\delta}} \\
1+r_{d}^{\delta}=\frac{\mu_{d}^{\delta}}{d^{\phi}} \\
1+\rho=\frac{\mu^{\gamma}}{d^{\delta}+M}
\end{gathered}
$$

Equation 21 states commodity market clearing conditions for prices in the two periods and in all states. Equation 22 states the loan market clearing conditions for interest rates applied by bank $\gamma$ and bank $\delta$ to corporate $\alpha$ and $\beta$ respectively. Equation 23 states the deposit market 
clearing condition for the deposit interest rate and equation 24 states the interbank market clearing condition for the interbank interest rate.

An equilibrium occurs when all agents maximize their expected payoffs/utilities and the market clearing conditions are satisfied. Let $P=$ $\left(g_{0}, g_{1}, g_{2}, r_{m}^{\gamma}, r_{m}^{\delta}, r_{d}^{\delta}, \rho\right), D^{\gamma}(P)=\left\{\left(m_{\alpha}^{\gamma}, \mu^{\gamma}, v_{1}^{\gamma}, v_{2}^{\gamma}\right):(3)-(6)\right.$ hold $\}$, $D^{\delta}(P)=\left\{\left(m_{\beta}^{\delta}, d^{\delta}, \mu_{d}^{\delta}\right):(11)-(14)\right.$ hold $\}, D^{h}=\left\{\left(b_{0}^{h}, q_{s}^{h}, \mu^{h}, v_{1}^{h}, v_{2}^{h}\right)\right.$ : $(16)-(17)$ hold $\}$ for $h=\alpha, \beta, D^{\phi}(P)=\left\{\left(d^{\phi}, b_{s}^{\phi}, q_{0}^{\phi}\right)\right.$ : (19) - (20) hold $\}$. An equilibrium is defined as the vector $\left(m_{\alpha}^{\gamma}, \mu^{\gamma}, v_{1}^{\gamma}, v_{2}^{\gamma}, m_{\beta}^{\delta}, d^{\delta}, \mu_{d}^{\delta}, b_{0}^{\alpha}\right.$, $\left.q_{s}^{\alpha}, \mu^{\alpha}, v_{1}^{\alpha}, v_{2}^{\alpha}, b_{0}^{\beta}, q_{s}^{\beta}, \mu^{\beta}, v_{1}^{\beta}, v_{2}^{\beta}, d^{\phi}, b_{s}^{\phi}, q_{0}^{\phi} ; g_{0}, g_{1}, g_{2}, r_{m}^{\gamma}, r_{m}^{\delta}, r_{d}^{\delta}, \rho\right)$ such that:

1) $\left(m_{\alpha}^{\gamma}, \mu^{\gamma}, v_{1}^{\gamma}, v_{2}^{\gamma}\right) \in \operatorname{Arg} \max _{\left(m_{\alpha}^{\gamma}, \mu^{\gamma}, v_{1}^{\gamma}, v_{2}^{\gamma}\right) \in D^{\gamma}(P)} \Pi^{\gamma}$

2) $\left(m_{\beta}^{\delta}, d^{\delta}, \mu_{d}^{\delta}\right) \in \operatorname{Arg} \max _{\left(m_{\beta}^{\delta}, \mu^{\delta}, \mu_{d}^{\delta}\right) \in D^{\delta}(P)} \Pi^{\delta}$

3) $\left(b_{0}^{h}, q_{s}^{h}, \mu^{h}, v_{1}^{h}, v_{2}^{h}\right) \in \operatorname{Arg} \max _{\left(b_{0}^{h}, q_{s}^{h}, \mu^{h}, v_{1}^{h}, v_{2}^{h}\right) \in D^{h}(P)} U^{h} \quad h=\alpha, \beta$

4) $\left(d^{\phi}, b_{s}^{\phi}, q_{0}^{\phi}\right) \in \operatorname{Arg} \max _{\left(d^{\phi}, b_{s}^{\phi}, q_{0}^{\phi}\right) \in D^{\phi}(P)} U^{\phi}$

5) (21)-(24) hold.

As for the computation of the equilibrium ${ }^{6}$, in line with the related literature we guess the first one by making hypotheses on interest rates and prices and numerically solving the five optimization problems ${ }^{7}$.

In order to solve the model we need to specify values to the exogenous variables. Even though the model is not calibrated with real data, we choose values that generate a reasonable equilibrium. The initial equilibrium is depicted in the Table 1 showing the equilibrium values of exogenous and endogenous variables.

The model is parametrized so that the capital requirements constraint for both banks is binding. As for the corporates, they have different risk features. Corporate $\beta$ is riskier than corporate $\alpha$ in the sense that it has a lower coefficient of risk aversion and its commodity and money endowments are more dispersed $\left(m_{s}^{h}, e_{s}^{h} h=\alpha, \beta\right.$ in Table 1$)$. As a consequence its repayment rate is lower and more dispersed in the initial equilibrium $\left(v_{s}^{h} h=\alpha, \beta\right.$ in Table 1$)$. According to the riskyness of corporates, the loan interest rate $r_{m}^{\gamma}$ applied to corporate $\alpha$ is lower than the rate $r_{m}^{\delta}$ applied to corporate $\beta$ in equilibrium. The model is solved assuming equal probability for expansion and recession for the second period: therefore the initial equilibrium represents a "neutral" situation in the sense that no biased forecasts about the business cycle is considered. We assume that the pit and ttc rating systems give the same risk weight and we consider this situation as the starting point for our

\footnotetext{
${ }^{6}$ For the existence of the equilibrium we refer to the more general model in Tso$\operatorname{mocos}(2003)$.

${ }^{7}$ The problem is solved with the Matlab Optimization Toolbox.
} 


\begin{tabular}{|l|l|l|l|l|l|l|}
\hline \multicolumn{7}{|l|}{ Exogenous variables and parameters } \\
\hline$c_{0}^{\gamma}$ & $c_{0}^{\delta}$ & $a^{\gamma}$ & $a^{\delta}$ & $p_{1}$ & $p_{2}$ & $M$ \\
\hline 0.13856 & 0.33412 & 0.08 & 0.08 & 0.5 & 0.5 & 0.38042 \\
\hline$e_{0}^{\phi}$ & $m_{0}^{\phi}$ & $u_{1}^{\phi}$ & $u_{2}^{\phi}$ & $a_{0}^{\phi}$ & $a_{1}^{\phi}$ & $a_{2}^{\phi}$ \\
\hline 6 & 2.0446 & 1.607 & 1.614 & 0.06 & 0.04 & 0.04 \\
\hline$e_{1}^{\alpha}$ & $e_{2}^{\alpha}$ & $m_{1}^{\alpha}$ & $m_{2}^{\alpha}$ & $a_{0}^{\alpha}$ & $a_{1}^{\alpha}$ & $a_{2}^{\alpha}$ \\
\hline 2.9 & 2.1 & 0.05 & 0.01 & 0.09914 & 0.115 & 0.182 \\
\hline$e_{1}^{\beta}$ & $e_{2}^{\beta}$ & $m_{1}^{\beta}$ & $m_{2}^{\beta}$ & $a_{0}^{\beta}$ & $a_{1}^{\beta}$ & $a_{2}^{\beta}$ \\
\hline 3 & 2 & 0.055 & 0.005 & 0.0778 & 0.102 & 0.187 \\
\hline Endogenous variables & \multicolumn{5}{l|}{} \\
\hline$m^{\gamma}$ & $\mu^{\gamma}$ & $\nu_{1}^{\gamma}$ & $\nu_{2}^{\gamma}$ & & & \\
\hline 1.4374 & 1.4288 & 0.97087 & 0.94823 & & & \\
\hline$m^{\delta}$ & $\mu_{d}^{\delta}$ & $d^{\delta}$ & & & & \\
\hline 1.4603 & 2.0855 & 0.9185 & & & & \\
\hline$b_{0}^{\alpha}$ & $\mu^{\alpha}$ & $q_{1}^{\alpha}$ & $q_{2}^{\alpha}$ & $\nu_{1}^{\alpha}$ & $\nu_{2}^{\alpha}$ & \\
\hline 1.4374 & 1.8687 & 1.4216 & 1.3169 & 0.93965 & 0.92151 & \\
\hline$b_{0}^{\beta}$ & $\mu^{\beta}$ & $q_{1}^{\beta}$ & $q_{2}^{\beta}$ & $\nu_{1}^{\beta}$ & $\nu_{2}^{\beta}$ & \\
\hline 1.4603 & 2.0152 & 1.3920 & 1.2749 & 0.85619 & 0.82495 & \\
\hline$q_{0}^{\phi}$ & $b_{1}^{\phi}$ & $b_{2}^{\phi}$ & $d^{\phi}$ & & & \\
\hline 2.8978 & 3.3763 & 3.3694 & 2.0446 & & & \\
\hline Interest rates and prices & pres & $g_{0}$ & $g_{1}$ & $g_{2}$ \\
\hline$r_{m}^{\gamma}$ & $r_{m}^{\delta}$ & $r_{d}^{\delta}$ & $\rho$ & 1 & 1.2 & 1.3 \\
\hline 0.3 & 0.38 & 0.02 & 0.1 & 1 & \\
\hline
\end{tabular}

Table 1: Initial equilibrium values

comparative statics. Table 2 shows the conditional and unconditional utilities/payoffs in equilibrium. The conditional utilities/payoffs in expansion are obviously higher than the ones in recession for all agents.

\begin{tabular}{|l|l|l|l|l|l|l|}
\hline & bank $\gamma$ & bank $\delta$ & & corporate $\alpha$ & corporate $\beta$ & household $\phi$ \\
\hline$\left.\Pi\right|_{E}$ & 0.3187 & 0.5899 & $\left.U\right|_{E}$ & 1.1649 & 1.1819 & 2.497 \\
\hline$\left.\Pi\right|_{R}$ & 0.2868 & 0.512 & $\left.U\right|_{R}$ & 0.5908 & 0.4288 & 2.323 \\
\hline$\Pi$ & 0.3027 & 0.55095 & $U$ & 2.1105 & 2.0998 & 4.935 \\
\hline
\end{tabular}

Table 2: Utilities/payoffs at the initial equilibrium

\section{Evaluation of rating systems}

In this section, we present the model results as for the evaluation of different rating systems within economic scenarios defined in terms of the state of the business cycle. In order to account for different rating 
systems, the risk weight on risky assets in the capital ratio formula is modelled in equation 7 as an increasing function of the PD mimicking the Basel II formula. The final aim of this paper is to compare two rating systems: one business cycle neutral (i.e. resembling a ttc rating) and the other business cycle dependent (i.e. resembling a pit rating). Specifically, the comparison of the two rating systems is performed both from the banks' point of view and from a welfare perspective.

We define a pit rating system as the one where the PD in equation 7 and hence the risk weight changes according to the recession probability, while a ttc rating system as the one where the PD does not change. In order to reproduce these two rating systems we assume that banks first estimate their obligors' PD in a situation of equally likely expansion and recession as in the initial equilibrium. When the recession probability changes, the PD under the pit system changes according to equation 8 whereas the PD under the ttc remains constant.

In order to perform the comparison between the two rating systems, we consider a change in the recession probability and evaluate the utilities/payoffs under the neutral rating system, where the change in the recession probabilty does not affect the capital requirements, and under the cycle-dependent system where the change in the recession probability changes the risk weights. We obtain new equilibria corresponding to different probabilities of recession by means of a comparative statics analysis and compare conditional and expected utilities/payoffs.

The focus of our analysis is on the assessment of the two rating systems rather than on the possibility that a bank would switch from the pit to the ttc rating system. This might be the case if we start from an expansionary state of the world and subsequently a recessionary one occurs. However, the banks would not be allowed by the regulators to do so since that would be commensurate to "cheating". This possibility merits further consideration ${ }^{8}$. The analysis of this case requires the extension of our model to three periods.

Under the ttc rating system, the recession probability change does not affect the risk weights. Table 3 shows the directional changes due to an increase in recession probability.

The increase in the recession probability makes consumption more preferable in $\mathrm{t}=0$, therefore commodity sales by the household in $\mathrm{t}=0$ $\left(q_{0}^{\phi}\right)$ decrease to allow for higher consumpion and, therefore, expenditures in $\mathrm{t}=1\left(b_{s}^{\phi}\right)$ decrease. Consequently, commodity prices increase in $\mathrm{t}=0$ whereas they decrease in both states in $t=1$.

\footnotetext{
${ }^{8}$ We are grateful for this observation to Charles Goodhart.
} 


\begin{tabular}{|c|c|c|c|c|c|c|c|c|c|c|c|}
\hline \multicolumn{12}{|c|}{ Banks decision variables } \\
\hline$m^{\gamma}$ & $\mu^{\gamma}$ & $\nu_{1}^{\gamma}$ & $\nu_{2}^{\gamma}$ & & $m^{\delta}$ & $\mu_{d}^{\delta}$ & $d^{\delta}$ & & & & \\
\hline$\uparrow$ & $\uparrow$ & $\downarrow$ & $\downarrow$ & & $\downarrow$ & $\downarrow$ & $\uparrow$ & & & & \\
\hline \multicolumn{12}{|c|}{ Corporates decision variables } \\
\hline$\overline{b_{0}^{\alpha}}$ & $\mu^{\alpha}$ & $q_{1}^{\alpha}$ & $\overline{q_{2}^{\alpha}}$ & $\overline{\nu_{1}^{\alpha}}$ & $\nu_{2}^{\alpha}$ & $b_{0}^{\beta}$ & $\mu^{\beta}$ & $q_{1}^{\beta}$ & $q_{2}^{\beta}$ & $\nu_{1}^{\beta}$ & $\nu_{2}^{\beta}$ \\
\hline$\uparrow$ & $\approx$ & $\downarrow$ & $\downarrow$ & $\downarrow$ & $\downarrow$ & $\downarrow$ & $\downarrow$ & $\downarrow$ & $\downarrow$ & $\downarrow$ & $\downarrow$ \\
\hline \multicolumn{12}{|c|}{ Household decision variables } \\
\hline$q_{0}^{\phi}$ & $b_{1}^{\phi}$ & $b_{2}^{\phi}$ & $d^{\phi}$ & & & & & & & & \\
\hline$\downarrow$ & $\downarrow$ & $\downarrow$ & $=$ & & & & & & & & \\
\hline \multicolumn{12}{|c|}{ Equilibrium prices/interest rates } \\
\hline$r_{m}^{\gamma}$ & $r_{m}^{\delta}$ & $r_{d}^{\delta}$ & $\rho$ & $g_{0}$ & $g_{1}$ & $g_{2}$ & & & & & \\
\hline$\downarrow$ & $\downarrow$ & $\downarrow$ & $\uparrow$ & $\uparrow$ & $\downarrow$ & $\downarrow$ & & & & & \\
\hline \multicolumn{12}{|c|}{ Utilities/Payoffs } \\
\hline$\Pi^{\gamma}$ & $\overline{\Pi^{\delta}}$ & $U^{\alpha}$ & $U^{\beta}$ & $U^{\phi}$ & & & & & & & \\
\hline$\downarrow$ & $\downarrow$ & $\downarrow$ & $\downarrow$ & $\downarrow$ & & & & & & & \\
\hline
\end{tabular}

Table 3: Directional changes due to an increase in recession probability under the ttc rating system

From the corporates' point of view, the increase in $g_{0}$ implies a decrease in counsumption $\left(x_{0}^{h}\right)$ and lower second period prices, together with lower expected endowment, produce less commodity sales $\left(q_{s}^{h}\right)$. The reduction in revenues results into lower repayment rates to banks in both states at $\mathrm{t}=1$. Bank $\gamma$, which is net borrower on the interbank market, reacts by reducing repayments to bank $\delta$ (net lender) in order to sustain its profitability. Moreover, since it cannot diversify, its demand for interbank loans $\left(\mu^{\gamma}\right)$ increases and it invests more in corporates. Hence the interbank interest rate increases while the loan interest rate decreases (this allows for the satisfaction of the capital requirements constraint). As for bank $\delta$, both investments become less profitable due to lower repayment rates, but the higher interbank rate leads to switching from loan to corporates to interbank deposits. Recalling that bank $\delta$ collects deposits from households, deposit demand $\left(\mu_{d}^{\delta}\right)$ decreases and thus the deposit interest rate decreases too, which again reduces second period revenues for household. The loan rate for corporate $\beta$ decreases despite the reduced supply since the demand decreases as well. In terms of utilities/payoffs, the increased recession probability induces a welfare reduction of all the agents. The opposite effects hold for a reduction in recession probability.

We now move to analyse the new equilibrium under the pit rating system. Table 4 shows the directional changes of the endogenous variables following an increase of the recession probability. 


\begin{tabular}{|c|c|c|c|c|c|c|c|c|c|c|c|}
\hline \multicolumn{12}{|c|}{ Banks decision variables } \\
\hline$m^{\gamma}$ & $\mu^{\gamma}$ & $\nu_{1}^{\gamma}$ & $\nu_{2}^{\gamma}$ & & $m^{\delta}$ & $\mu_{d}^{\delta}$ & $d^{\delta}$ & & & & \\
\hline$\downarrow$ & $\downarrow$ & $\uparrow$ & $\uparrow$ & & $\uparrow$ & $\downarrow$ & $\downarrow$ & & & & \\
\hline \multicolumn{12}{|c|}{ Corporates decision variables } \\
\hline$\overline{b_{0}^{\alpha}}$ & $\mu^{\alpha}$ & $q_{1}^{\alpha}$ & $\overline{q_{2}^{\alpha}}$ & $\overline{\nu_{1}^{\alpha}}$ & $\nu_{2}^{\alpha}$ & $b_{0}^{\beta}$ & $\mu^{\beta}$ & $q_{1}^{\beta}$ & $q_{2}^{\beta}$ & $\nu_{1}^{\beta}$ & $\nu_{2}^{\beta}$ \\
\hline$\downarrow$ & $\downarrow$ & $\downarrow$ & $\downarrow$ & $\uparrow$ & $\uparrow$ & $\uparrow$ & $\downarrow$ & $\downarrow$ & $\downarrow$ & $\uparrow$ & $\uparrow$ \\
\hline \multicolumn{12}{|c|}{ Household decision variables } \\
\hline$q_{0}^{\phi}$ & $b_{1}^{\phi}$ & $b_{2}^{\phi}$ & $d^{\phi}$ & & & & & & & & \\
\hline$\downarrow$ & $\downarrow$ & $\downarrow$ & $=$ & & & & & & & & \\
\hline \multicolumn{12}{|c|}{ Equilibrium prices/interest rates } \\
\hline$r_{m}^{\gamma}$ & $r_{m}^{\delta}$ & $r_{d}^{\delta}$ & $\rho$ & $g_{0}$ & $g_{1}$ & $g_{2}$ & & & & & \\
\hline$\downarrow$ & $\downarrow$ & $\downarrow$ & $\downarrow$ & $\uparrow$ & $\downarrow$ & $\downarrow$ & & & & & \\
\hline \multicolumn{12}{|c|}{ Utilities/Payoffs } \\
\hline$\Pi^{\gamma}$ & $\overline{\Pi^{\delta}}$ & $U^{\alpha}$ & $U^{\beta}$ & $U^{\phi}$ & & & & & & & \\
\hline$\uparrow$ & $\downarrow$ & $\downarrow$ & $\downarrow$ & $\downarrow$ & & & & & & & \\
\hline
\end{tabular}

Table 4: Directional changes due to an increase in recession probability under the pit rating system

The main difference lies in the effect of recession probability on Basel II risk weights. Under the pit rating system, the increase in the recession probability for both banks means an increase in the risk weights. This induces a direct effect on banks' portfolio in stark contrast with the ttc rating system. Recalling the limited participation hypothesis, the risk weight of bank $\delta$ is affected more strongly due to the higher dispersion of corporate $\beta$ 's default rates. On the other hand, bank $\gamma$, which cannot diversify, is forced to reduce its credit extension to corporates, and this reduction is associated to a decrease in interbank borrowings, that in turn lowers the interbank interest rate. Moreover, the increased expected penalty for default produces an increase in repayment rates, that is enhanced further by increased corporate repayment rates (as clarified later), which more than compensates the negative effect of higher risk weights on credit extension of bank $\delta$ in the interbank market. The reduced interbank interest rate induces bank $\delta$ to switch from these to corporate loans. Given the reduced profitability of these activities, bank $\delta$ reduces deposit demand thus causing a reduction in the deposit interest rate. However, this effect is much weaker than under ttc.

The reduced deposit interest rate means less liquidity in $t=1$ for households, who reduce expenditures for commodities implying lower prices. Moreover, since consumption in $\mathrm{t}=0$ becomes relatively more preferable, commodity sales in $\mathrm{t}=0$ and expenditures for commodities in $t=1$ decrease, having similar effects on prices as under the ttc. The re- 
duction in second period commodity prices and the decreased expected commodity endowment cause corporates to reduce commodity selling and money borrowing. However, the increased expected default penalty more than compensates the effect on repayments which ultimately increase. The risk weights, however, are still higher than in the initial equilibrium. The total effect on interest rates for corporate loans is a reduction which is more pronounced for corporate $\beta /$ bank $\delta$. The increase in the recession probability generates a welfare reduction for all agents except bank $\gamma$. This seemingly counterintuitive effect is due to two reasons. The first reason is the increase in corporates repayment rates and the second one is the reduction in the interbank interest rate. The opposite effects hold for a reduction of the recession probability.

We now turn to the welfare comparison between the neutral and the cycle-dependent rating systems. We consider two different cases: one in which a recession is expected, i.e. an increase in the recession probability, and the other in which an expansion is expected (i.e. a reduction in the recession probability). When the recession becomes more likely, the pit system turns out to be more convenient for all the agents except for bank $\delta$. This is mainly due to the fact that it suffers from the lower interbank interest rate, which implies lower costs for bank $\gamma$ and profits for bank $\delta$. In addition, under the pit system there is a stronger reduction in corporates interest rates and a lower reduction in deposit rates with respect to the ttc system. This means higher utility for corporates and househld respectively at the expense of bank $\delta$. The opposite effects prevail when an expansion is more likely. Therefore the preference for the pit or the ttc rating system depends on the point in the cycle the economy is. Put differently, the crucial determinant for the rating system selection is the expectation relatively to the evolution of the business cycle over the time horizon considered for the second period.

We now focus on the comparison of the pit and the ttc system from the banks point of view. The net lender bank $(\delta)$ would prefer the ttc rating system under a pessimistic business cycle scenario, while it would prefer the pit system under an optimistic one; the opposite holds for the net borrower bank $(\gamma)$. Assuming that the business cycle is correctly forcasted, so that a recession probability higher than 0.5 turns out in an actual recession in $\mathrm{t}=1$ (and vice versa for probability lower than 0.5 ), we can consider the case of high recession probability and compare conditional payoffs in case of realized recession. Clearly the recession payoffs are lower than the expansion ones. However, bank $\delta$ would be more satisfied (i.e. less damaged by recession) under ttc system since the risk characteristics of corporate $\beta$ cause a strong increase in risk weights 
(stronger than for corporate $\alpha$ ), the deposit rate decreases more strongly than under the pit system and the interbank rate increases. However, on the other hand and partly due to the same reasons, bank $\gamma$ (as well as the other agents) achieves higher payoff under the pit system. Similar considerations hold in case of expansion.

We hasten to add that if banks were free to choose their rating system, their preference would change according to the state of the business cycle. We analyse the direction of increases and reductions in payoffs moving from the ttc to the pit rating system in the two different phases of the cycle. The increase in payoff is higher than the decrease for bank $\gamma$ : this means that bank $\gamma$ would choose the pit rating system ${ }^{9}$. The preference is less clear cut for bank $\delta$. This result is driven by the role of bank $\delta$ in the interbank and deposit markets and by the risk characteristics of its debtors compared to bank $\gamma$. Assuming again that the forecast of business cycle is correct, in case of recession (expected and realized) the payoff for bank $\gamma$ is higher under pit while it is higher under ttc for bank $\delta$; the opposite hold in case of expansion. Moreover, by considering the other agents' conditional utilities, they all are better off under pit in case of recession and the opposite holds in expansion. However, by comparing the size of the utilities/payoffs in the two business cycle states, we can draw a comparison on the whole cycle: it emerges that the increase is higher than the decrease for bank $\gamma$ and for both corporates, while it is lower for bank $\delta$ and for the household. Consequently, these results suggest that, assuming correct forecasting, net lender banks and depositors would be better off under ttc while net borrower banks and corporates would be better off under pit.

\section{Concluding remarks}

Recapitulating, in the light of the importance of the procyclicality issue related to the introduction of Basel II, we evalute different rating systems within a general equilibrium model. We set up a model with two heterogeneous banks, two corporates and an household and we solve numerically the model to find an initial equilibrium. Then, we evaluate a neutral and a cycle-dependent rating system. The main issue analysed is the comparison between the two rating systems from the banks' point of view. The preference for pit or ttc rating systems depends on the point in the cycle and on the bank's features. Specifically, based on the

\footnotetext{
${ }^{9}$ The reason is that bank $\gamma$ would prefer either a procyclical or a countercyclical rating system depending on the phase of the business cycle (consistently with Caterineu-Rabell et al. 2005). However, since the countercyclical rating is not allowed, bank $\gamma$ chooses the ttc rating system when it would have chosen the countercyclical one.
} 
comparison of conditional and expected payoffs, it emerges that the net lender bank, which also extends loans to the riskier corporate, prefers the ttc rating, while the net borrower bank prefers the pit system when a recession is expected. The result is weaker, in particular the bank $\delta$ preference is less clear cut, over the whole cycle. These conclusions arise from the various interaction channels that are at work in our model. The general equilibrium framework allows to highlight and quantify the various effects and trade offs and, consequently, to focus on the important ones.

Our results are consistent with the conclusion of Catarineu-Rabell et. al (2005), however, since we have introduced more heterogeneity, the mechanisms through which they hold are more complicated. In addition, our model reveals the different behaviour between banks characterised by different portfolio composition and degree of diversification. This point has already been emphasized in Goodhart et al. (2004).

The next logical step in our research agenda is twofold. On one hand, we plan to test the robustness of the results to different parametrizations of the model (e.g. different levels of capitalization) and, to the extent that data availability allows it, to calibrate the model on real data. On the other hand, in order to capture feedback effects of capital requirements on the business cycle, it would be useful to add a third period to the present model. Both these extensions would help to analyse the recent crisis. The Basel I constant risk weights, as well as the Basel II risk weights under the standardised apporach, are consistent with a ttc rating system. However, our analysis suggests that the adoption of a ttc rating system rather than a pit system by big banks would lead to higher defaults and low profits in recession. In conclusion, a more pessimistic economic outlook coupled with the ttc rating system may precipitate into financial fragility according to the definition suggested by Goodhart et al. (2006). This observation sheds some light to the current financial crisis. 


\section{References}

[1] Bangia A., Diebold F., Kronimus A., Schagen C., Schuermann T., 2002. Ratings migration and the business cycle, with application to credit portfolio stress testing. Journal of Banking \& Finance, 26, 445-474.

[2] Basel Committee on Banking Supervision, (BCBS), 2006. International convergence of capital measurement and capital standards A revised framework. June 2006.

[3] Borio C., Furfine C., Lowe P., 2001. Procyclicality of the financial system and Financial stability: issues and policy options. BIS Paper, 1 .

[4] Catarineu-Rabell E., Jackson P., Tsomocos D., 2005. Procyclicality and the new Basel accord: banks'choice of loan rating system. Economic Theory, 26, 537-557.

[5] Daniellson J., Embrechts P., Goodhart C., Keating C., Muennich F., Renault O., Shin H. S., 2001. A academic response to Basel II. London School of Economics, Financial Markets Group, Special Paper 130.

[6] Goodhart C.A.E., Sunirand P., Tsomocos D., 2006. A model to analyse financial fragility. Economic Theory, 27, 107-142.

[7] Goodhart C.A.E., Sunirand P., Tsomocos D., 2005. A risk assessment model for banks. Annals of Finance, 1, 197-224.

[8] Goodhart C.A.E., Sunirand P., Tsomocos D., 2004. A model to analyse financial fragility: applications. Journal of Financial Stability, 1, 1-30.

[9] Gordy M., Howells B., 2006, Procyclicality in Basel II: can we treat the disease without killing the patient?. Journal of Financial Intermediation, 15, 395-417.

[10] Jokivuolle E., Vesala T., 2007. Portfolio effects and efficiency of lending under Basel II. Bank of Finland Research, Discussion Papers 13.

[11] Kashyap A., Stein J., 2004. Cyclical implications of the Basel II Capital Standards. Federal Reserve Bank of Chicago Economic Perspective, 1st Quarter, 18-31.

[12] Masschelein N., 2007. Monitoring pro-cyclicality under the capital requirement directive: preliminary concepts for developing a framework. Natiolal Bank of Belgium, Working Paper Document 120.

[13] Nickell P., Perraudin W., Varotto S., 2000. Stability of rating transitions. Journal of Banking \& Finance, 24, 203-227.

[14] Pederzoli C., Torricelli C., 2005. Capital requirements and business cycle regimes: forward-looking modelling of default probabilities. Journal of Banking \& Finance, 29, pp. 3121-3140. 
[15] Repullo R., Suarez J., 2007. The procyclical effects of Basel II. Working paper.

[16] Tsomocos D., 2003. Equilibrium analysis, banking and financial instability. Journal of Mathematical Economics, 39, 619-655. 